\title{
ENVIA GARCIAI, A NEW GENUS AND SPECIES OF MYGALOMORPH SPIDERS (ARANEAE, MICROSTIGMATIDAE) FROM BRAZILIAN AMAZONIA
}

\author{
Ricardo Ott ${ }^{1}$ \\ Hubert Höfer ${ }^{2}$
}

\begin{abstract}
The genus Envia, comprising only the new species Envia garciai, is proposed. These small mygalomorph spiders were abundantly collected in soil cores and litter samples in primary rain forests near Manaus, Amazonas, Brazil.

KEYWORDS. Envia, Pseudonemesiini, Neotropical, Amazonia, taxonomy.
\end{abstract}

\section{INTRODUCTION}

Microstigmatids are small ground-dwelling and free-living spiders which make little use of silk (Griswold,1985 apud DippenaAR-Schoenman \& Jocqué, 1997). At present, thirteen species are known worldwide (Platnick, 2003) and only the monospecific genus Ministigmata Raven \& Platnick, 1981, including the species $M$. minuta, are know from Brazil.

The family Microstigmatidae was proposed by Raven \& Platnick (1981), who removed the group Microstigmateae from Dipluridae and elevated it to the family rank. These authors also transferred the subfamily Pseudonemesiinae from Ctenizidae to Microstigmatidae. Platnick \& Forster (1982) established the monotypic genus Micromygale and the subfamily Micromygalinae, transforming Pseudonemesiinae to a tribe within Microstigmatinae.

RAVEN (1985) considered four autoapomorphies to sustain the monophyly of Microstigmatidae: round booklung apertures, an elevated thorax as high behind the fovea as the caput, domed apical segments of the posterior lateral spinnerets, and a pustulose or scaly cuticle. The new species described here shares three of the four characters, but the posterior lateral spinnerets are long and their apical segment is digitiform.

GoLoвоғF (1995) included in this family Speleocteniza ashmolei Gertsch, 1982 and Xenonemesia platensis Goloboff, 1989, both transferred from Nemesiidae. Also,

\footnotetext{
1. Museu de Ciências Naturais, Fundação Zoobotânica do Rio Grande do Sul, Rua Dr. Salvador França, 1427, 90690-000, Porto Alegre, RS, Brazil. (aracno@fzb.rs.gov.br)

2. Staatliches Museum für Naturkunde Karlsruhe, Post Box 111364, D-76063, Karlsruhe, Germany. (hubert.hoefer@smnk.de)
} 
he modified the family diagnosis and consider microstigmatids recognizable by "rounded book-lungs opennings, in conjunction with extremely shortened posterior lateral spinnerets (often with spigots only on the apical article), glabrous integument, and scopula on anterior tarsi very ligth to absent".

The general appearance of the herein described species is similar to Pseudonemesia parva Caporiacco, 1955 (Raven \& Platnick, 1981). Two characters described by RAVEn \& Platnick (1981) for Pseudonemesia Caporiacco, 1955 are present in these spiders: the scaly cuticle without pustules and the corrugated trichobothrial bases. However, they are easily distinguished by having four spinnerets, with much longer posterior laterals. Pseudonemesia species have only two spinnerets. Therefore, we decide to propose a new genus in Pseudonemesiini.

\section{MATERIAL AND METHODS}

The material examined was obtained from litter and soil samples collected from the experimental sites of Embrapa Amazônia Ocidental and extracted by a Berlese-Tullgren apparatus. Material is deposited in Instituto Nacional de Pesquisas da Amazônia, Manaus (INPA), Museu de Ciências Naturais, Fundação Zoobotânica do Rio Grande do Sul, Porto Alegre (MCN), Instituto Butantan, São Paulo (IBSP) and Staatliches Museum für Naturkunde Karlsruhe, Karlsruhe (SMNK). All measurements are in millimeters. Morphological nomenclature follows RaVEN (1985).

\section{Envia gen. nov.}

Type species. Envia garciai sp. nov.

Etymology. The generic name is an arbitrary combination of letters. The gender is feminine.

Diagnosis. Envia can be distinguished from Micromygale, Ministigmata and Pseudonemesia by the presence of four spinnerets (figs. 1, 3, 10); from Microstigmata Strand, 1932 by the longer posterior lateral spinnerets (around three times longer than anterior laterals).

Description. Within the description of the species.

\section{Envia garciai sp. nov.}

(Figs. 1-21)

Types. Holotype $\sigma$ and paratype $\subsetneq$, Berlese samples taken in a primary forest at Embrapa Amazônia Ocidental, Rodovia AM-010 km 30, Manaus, Amazonas, Brazil (253’36”S, 5958’22’W), 10.IX.1997, H. Höfer et al. (INPA). Paratypes: ๖, , , 23.VII.1997

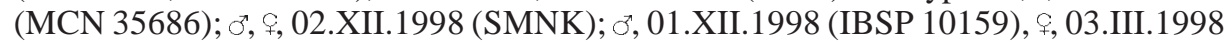
(IBSP 10160); all taken with same methodology, locality and by same collectors as the holotype. Ocidental.

Etymology. Named in honor of Marcos Garcia, researcher at Embrapa Amazônia

Diagnosis. Same of the genus.

Description. Holotype 3 . Coloration in alcohol uniformly yellowish, abdomen pale. Body covered with few setae. Carapace suboval, glabrous, with few bristles at the border, caput domed, fovea straigth, transverse, situated in the posterior third of the carapace. Eigth eyes on a low tubercle. Sternum domed, covered with bristles. 


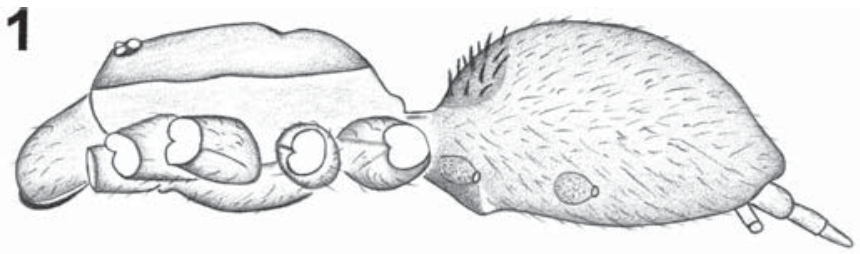

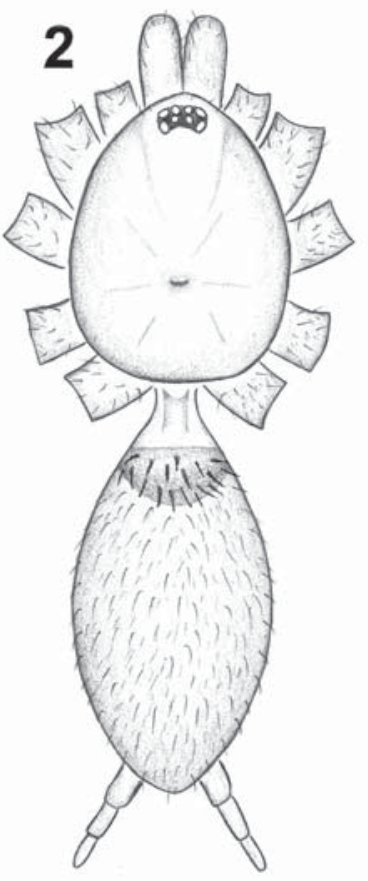

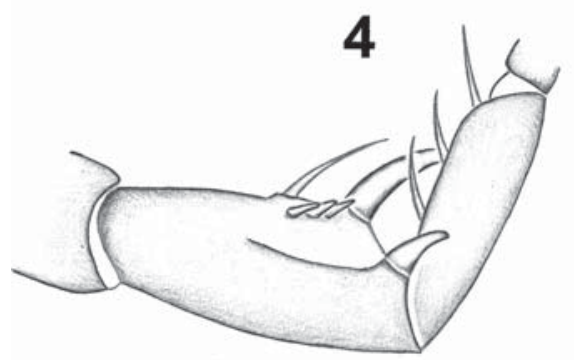

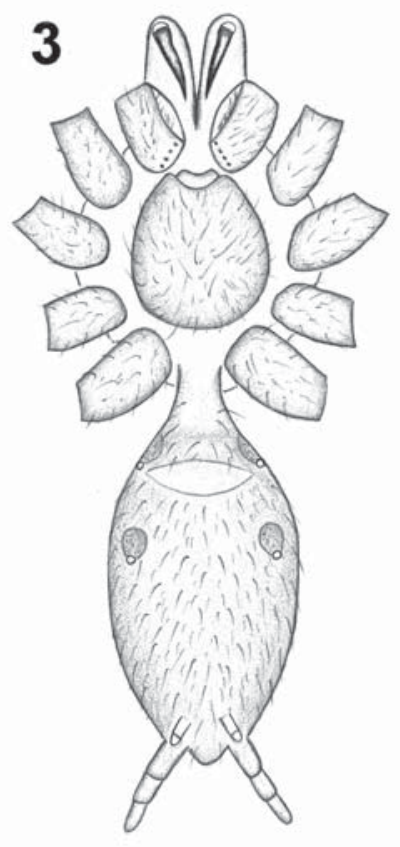

5

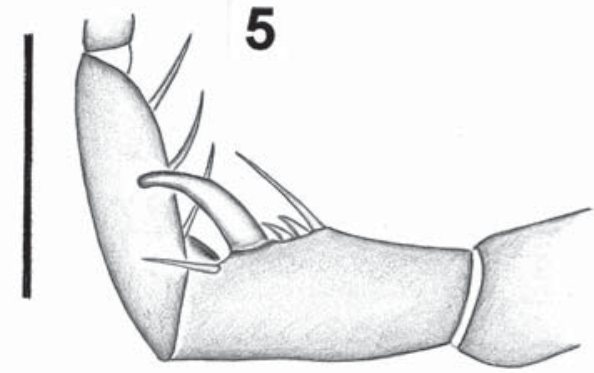

Figs. 1-5. Envia garciai sp. nov. 1-3, cephalothorax and abdomen: 1, lateral; 2, dorsal; 3, ventral; 4, 5, tibia and metatarsus of left leg I: 4, retrolateral; 5, prolateral. Scale bars: figs. 1-3, $1 \mathrm{~mm}$; figs. $4,5,0.5 \mathrm{~mm}$. 

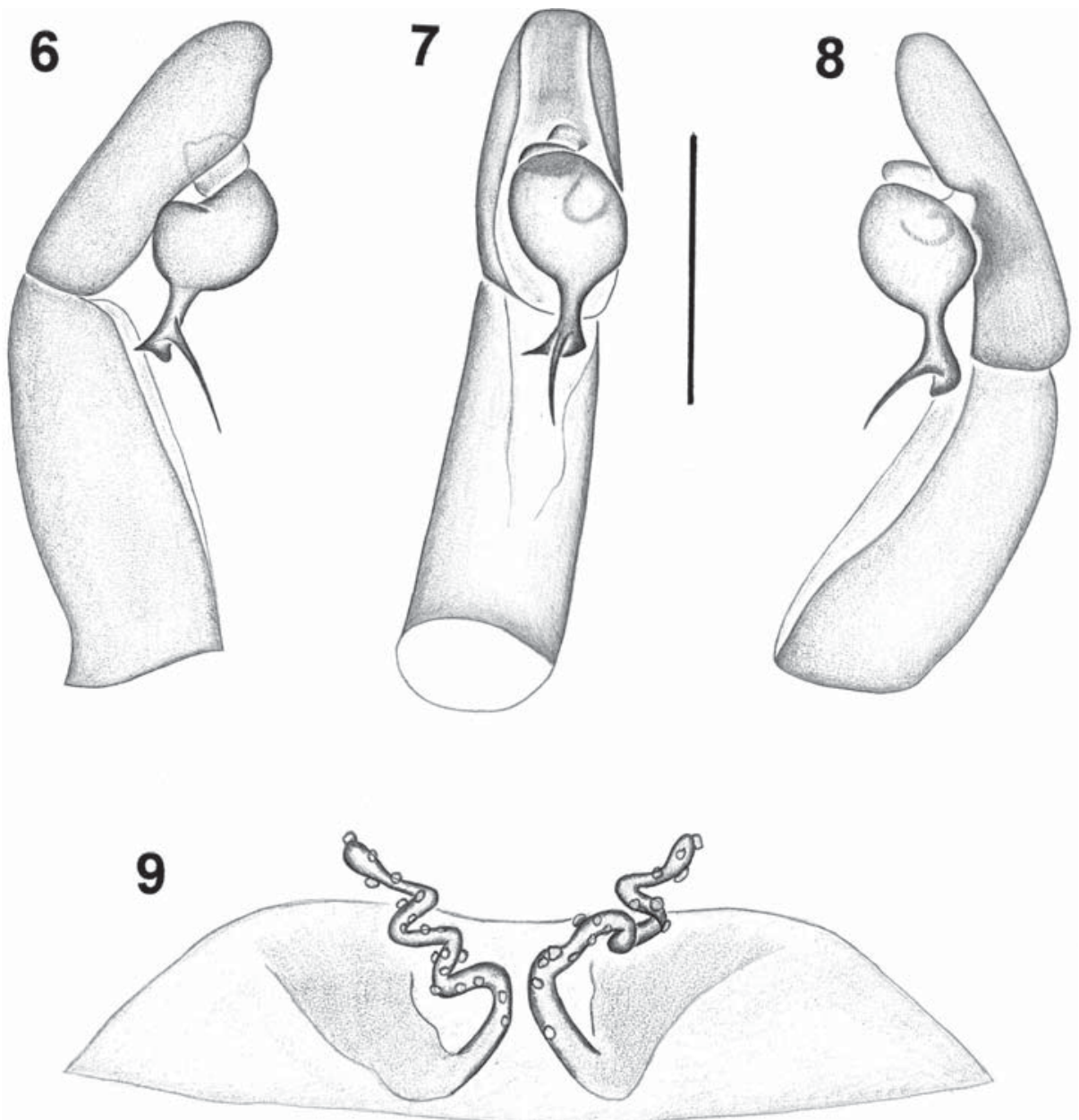

Figs. 6-9. Envia garciai sp. nov. 6-8, left palp: 6, prolateral; 7, ventral; 8, retrolateral; 9, spermathecae, dorsal. Scale bars: figs. $6-8,0.25 \mathrm{~mm}$; fig. $9,0.1 \mathrm{~mm}$.

Labium anteriorly excavated, without cuspules, with bristles in its anterior part. Palpal coxae covered with bristles, four cuspules (sometimes five) in a straigth line at base (figs. 3, 16), weak serrula (fig. 17). Cheliceral furrow with two rows of teeth; the prolateral row with eigth smaller teeth, the retrolateral row with 6 larger teeth (fig. 18). Leg formula 4123. Legs with bristles and spines; scaly cuticle and corrugated trichobothrial bases (figs. 12,13); scopula absent; spurs only at tibia I. Legs spination: no spines on tarsi, all femurs with four dorsal curved strong bristles, tibia and metatarsus of legs III and IV very spiny. Leg I: tibia v2 (plus clasping spur and four 

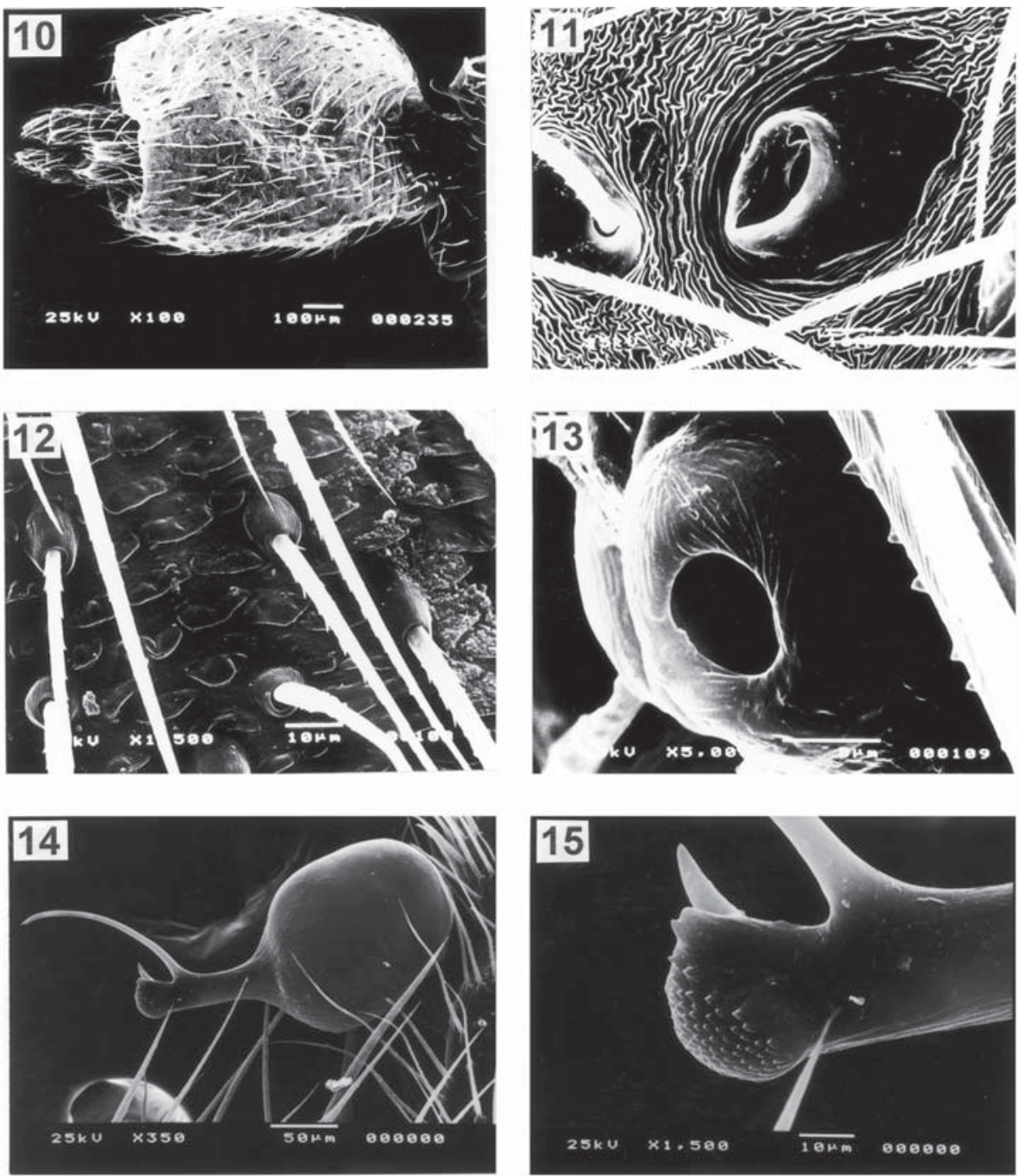

Figs. 10-15. Envia garciai sp. nov. 10, abdomen, ventral; 11, booklung aperture; 12, cuticule of tarsus I; 13, trichobothrial base of tarsus I; 14,15, left copulatory bulb: 14, retrolateral; 15, distal end. shorter spurs, figs. 4, 5), metatarsus v4; leg II: tibia p1, v4, metatarsus, p2, v5; leg III: patella p1, r1; leg IV: patella p1,r1. Three claws on all tarsi. Paired claws with two rows, each with four (leg IV) to eleven pairs of teeth (leg I) (figs. 19-21). Four to five trichobothria in an irregular row at tarsi, metatarsi and tibiae. Palp with sligthly incrassate tibia, tarsus elongated and excavated (figs. 6-8). Bulb inserted subapically, directed parallel to the cymbium towards the base. Embolus thin and curved, arising laterally from the complex end of the bulb which presents an enlarged head-like 

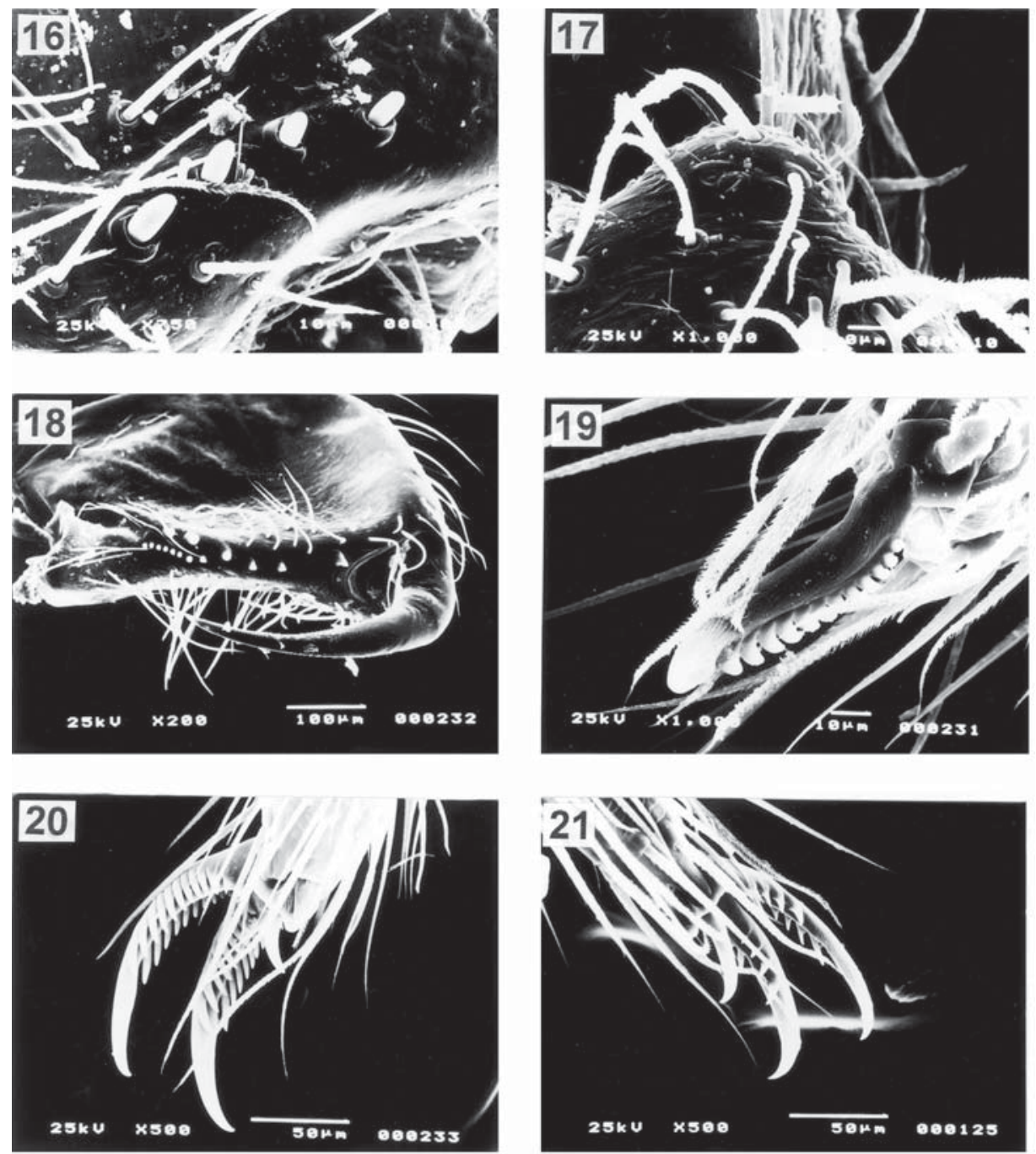

Figs. 16-21. Envia garciai sp. nov. 16, cuspules at base of palpal coxa; 17, serrula; 18, chelicera, ventral; 19, tarsal claw of female palp; 20, leg I, tarsal claw; 21, leg IV, tarsal claw.

structure with a short subapical prolateral spine (figs. 14, 15). Abdomen glabrous, with sparse erected bristles, anterior rounded dorsal scutum covered with thickened bristles (figs. 1, 2). Rised booklung apertures border (fig. 11). Four spinnerets, anterior about one third of length of the posterior, which are relative long, about one third of the length of abdomen (figs. 1, 3, 10).

Measurements. Total length including chelicerae, 3.20. Carapace 1.15 long, 0.96 wide. Ratio of eye diameters, ALE:AME:PLE:PME, 4:2:3:2; AME distance narrower 
than distance to PME. Ocular area 0.22 wide, 0.11 long. Sternum 0.66 long, 0.60 wide. Labium 0.16 long, 0.11 wide. Palpal coxae 0.36 long, 0.23 wide. Leg I: femur 0.99, patella 0.66 , tibia 0.55 , metatarsus 0.52 , tarsus 0.41 ; leg II: $0.85,0.49,0.52,0.55,0.41$; leg III: 0.74, 0.30, 0.52, 0.66, 0.49; leg IV: 0.99, 0.52, 0.88, 0.99, 0.58. Abdomen 1.37 long, 0.88 wide.

Paratype $\subsetneq$ (INPA). As in male except noted. Leg formula: 4132. Spination: leg I, tibia v2, metatarsus v4; leg II, tibia v2, metatarsus, v4. Palpal claw curved, with twelve teeth (fig. 19). Genitalia with two thin, long and twisted spermathecae (fig. 9).

Measurements. Total length including chelicerae, 3.34. Carapace, 1.12 long, 0.88 wide. Sternum 0.60 long, 0.57 wide. Labium 0.25 long, 0.11 wide. Palpal coxae 0.33 long, 0.25 wide. Abdomen 1.53 long, 0.96 wide.

Aditional examined material. BRAZIL, Amazonas: Manaus, 8 of, 25 \&, 16 juveniles, 23.VII.1997-04.III.1999, same locality of types (Berlese funnels), H. Höfer et al. (INPA); 5 §, IV.1991, Reserva Ducke (2 $55^{\prime} 12^{\prime \prime}$ S, 5958'48' W) (pitfall traps), H. Höfer et al. (SMNK).

Natural History. Spiders were collected in soil and litter in undisturbed rainforests, where they are quite abundant, reaching up to $17 \%\left(37 \mathrm{ind} . / \mathrm{m}^{2}\right)$ of the total spider abundance or $9 \%\left(9.2 \mathrm{mg} / \mathrm{m}^{2}\right)$ of the total spider biomass taken with litter and soil core samples (Berlese Funnels). Lower abundances were registered in secondary forests and agricultural systems (unpublished data). We consider these spiders belonging to the guild of litter stalkers, together with Masteria L. Koch, 1873 species (Dipluridae) and species of Oonopidae, Caponiidae and Palpimanidae (HöFER \& BRESCOVIT, 2001).

Acknowledgments. To all colleagues of the SHIFT project (Studies on human impact on forests and floodplains in the Tropic) from Embrapa, INPA and SMNK.

\section{REFERENCES}

Dippenate-Schoenman, A. S. \& Jocqué, R. 1997. African spiders, an identification manual. Pretoria, Plant Protection Research Institute. 392p.

Goloboff, P. A. 1995. A revision of the South American spiders of the family Nemesiidae (Araneae, Mygalomorphae). Part I: species from Peru, Chile, Argentina and Uruguay. Bull. Am. Mus. nat. Hist., New York, (224):1-189.

HöFer, H. \& BRESCOvit, A. D. 2001. Species and guild structure of a neotropical spider assemblage (Araneae) from Reserva Ducke, Amazonas, Brasil. Andrias, Karlsruhe, 15:99-119.

Platnick, N. I. 2003. The world spider catalog, version 3.5. American Museum of Natural History, on line at http://research.amnh.org/entomology/spiders/catalog 81-87/index.html. 24.04.03.

Platnick, N. I. \& Forster, R. R. 1982. On the Micromygalinae, a new subfamily of mygalomorph spiders (Araneae, Microstigmatidae). Am. Mus. Novit., New York, (2734):1-13.

Raven, R. J. 1985. The infraorder Mygalomorphae (Araneae): cladistics and sistematics. Bull. Am. Mus. Nat. Hist., New York, (182):1-180.

Raven, R. J. \& Platnick, N. I. 1981. A revision of the American spiders of the family Microstigmatidae (Araneae, Mygalomorphae). Am. Mus. Novit., New York, (2707):1-20.

Recebido em 25.11.2002; aceito em 02.07.2003. 